\title{
Эмоциональная основа организационного вандализма: теоретическая модель
}

\section{Ольга В. Кружкова“, Ирина В. Девятовская, Ирина В. Воробьева}

Уральский государственный педагогический университет, г. Екатеринбург, Российская Федерация

${ }^{*}$ E-mail: galiat1@yandex.ru

\begin{abstract}
Аннотация
Ввеление. В статье рассматривается возможность объяснения организационного вандализма через эмоциональные проявления ^ичности персонала. Несмотря на значительный ущерб, причиняемый персоналом материальной, информационной и социальной среде компании, подобная фрорма Аеструктивного поведения взрослого человека практически не изучается, в научной литературе представлены только разрозненные $а$ анные об агрессивных проявлениях персонала на рабочем месте (корпоративный саботаж, моббинг, халатность и пр.). В научной митературе отсутствуют описания предикторов ванАализма взрос^ого, не рассматриваются механизмы возникновения подобной стратегии взаимодействия человека с организационной среАой, что снижает потенциальную эдроективность от разрабатываемых программ и преАлагаемых методов по борьбе и преАупрежАению вандального поведения персонала. Новизна исследования заключается во введении и обосновании понятия «организационный вандализм» персонала, а также раскрытии его эмоциональной основы.
\end{abstract}

Теоретическое обоснование. Разработка понятия «организационный ванАализм» и модели его эмоциональной основы осуществлялись с применением метоАа теоретического моделирования. При описании эмоциональной основы организационного ванАализма авторы используют положения эволюционной теории эмоций Р. ПАутчика. Это Аает возможность соотнесения эмоций, переживаемых человеком в организационной среде, и различных вилов ванАальных Аействий, спровоцированных ими.

Результаты. Была сорормирована модель, гАе выАеляются восемь основных виАОв вандализма персонала в организации, связанных с первичными (базовыми) эмоциями: агрессивный, экзистенциальный, конорормный, случайный, реактивный, некомпетентности, отчужАения, среАовой. При «смешении» первичных эмоций возникают более сложные эмоциональные переживания, на основе которых также формируются отАельные виды вандализма персонала на рабочем месте, такие, как вандализм модернизации, стяжательный, ^юбопытствующий, мстительный, «циничный», панический, конкурентный и Ар. 
ПСИХОЛОГИЯ ТРУДА

ОбсужАение результатов. Аелается вывоА, что Использование преАложенной теоретической МоАели эмоциональной основы организационного ванАализма АОлЖно быть встроено в комп^ексную систему учета ^ичностных и организационных фракторов Аеструктивного поведения персона^а Аля его профииактики и предупрежАения.

\section{КАючевые слова}

ван $\triangle$ वлизм, ванАальное поведение, Аеструктивное повеАение, Аевиации, организационный ванАализм, корпоративный саботаж, агрессия, персона^, эмоции, поведение

\section{Основные положения}

- Аеструктивное поведение персонала в организации может быть реализовано в фрорме организационного ванАализма; инициация Аанной активности Аичности связана с переживаемыми ею эмоциональными состояниями;

- за основу изучения эмоциональной основы организационного вандализма была взята теория Р. Плутчика, позволяющая вылелить восемь основных и шестнадцать АОполнительных виАОв Аанного повеАения;

- использование созАанной теоретической модели эмоциональной основы вандализма персонала в практике профиияктической работы с Аеструктивным поведением на рабочем месте Аолжно учитывать специфический набор фракторов конкретной организационной среды, выступающих триггерами вандализма.

\section{Для цитирования}

Кружкова О. В., Девятовская И. В., Воробьева И. В. Эмоциональная основа организационного вандализма: теоретическая модель // Российский психологический журнал. 2018. T. 15, № 4. C. 179-205. DOI: 10.21702/rpj.2018.4.8

Материалы статьи получены 30.09.2017

UDC 316.624.2

DOI: $10.21702 /$ rpj.2018.4.8

\section{Emotional Basis of Organizational Vandalism: A Theoretical Model}

\section{Olga V. Kruzhkova*, Irina V. Deviatovskaia, Irina V. Vorobyeva}

Ural State Pedagogical University, Ekaterinburg, Russian Federation

*Corresponding author. E-mail: galiat1@yandex.ru

\section{Abstract}

Introduction. This paper considers the possibility of explaining organizational vandalism through personality emotional manifestations in employees. Despite the fact that 


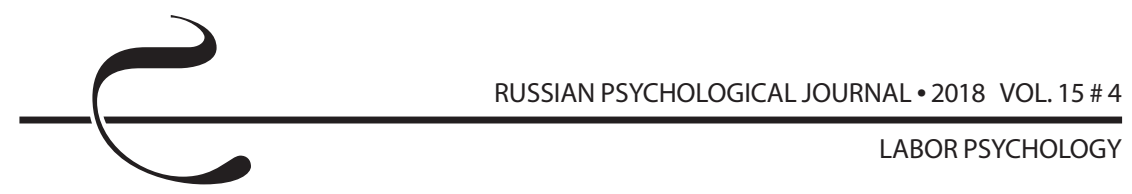

company employees often cause considerable damage to its material, information, and social environment, little attention has been devoted to studying such a form of destructive behavior in adults. Previous studies have taken into account only disparate data on employees' aggressive manifestations in the workplace (corporate sabotage, mobbing, negligence, etc.). In the scientific literature, scant attention has been paid to the predictors of adult vandalism and formation mechanisms of this type of human interaction with the organizational environment. This reduces the potential effectiveness of the programs and measures designed to prevent and combat vandal behavior in employees. This study introduces the concept of 'organizational vandalism' among company employees and attempts to discover its emotional basis.

Theoretical Basis. The 'organizational vandalism' concept and the model of its emotional basis were developed using the method of theoretical modeling. The authors relied on Plutchik's evolutionary theory of emotions to describe the emotional basis of organizational vandalism. This enabled them to correlate emotions experienced by individuals in organizational environments with various vandal behaviors provoked by them.

Results. The model of organizational vandalism developed by the authors included eight basic types of employees' vandalism related to primary (basic) emotions. These were aggressive, existential, conformal, incidental, reactive, and environmental types of vandalism and also vandalism of incompetence and vandalism of alienation. 'Mixing' primary emotions leads to more complex emotional experiences, which form the basis for certain types of employees' vandalism in the workplace including vandalism of modernization and also its possessive, curious, vindictive, 'cynical', panic, and competitive types.

Discussion. The proposed theoretical model of the emotional basis of organizational vandalism should be integrated into a comprehensive system that would consider personal and organizational factors to prevent destructive behavior in company employees.

\section{Keywords}

vandalism, vandal behavior, destructive behavior, deviations, organizational vandalism, corporate sabotage, aggression, company personnel, emotions, behavior

\section{Highlights}

- Employees' destructive behavior can manifest itself in the form of organizational vandalism. Individuals' emotional states initiate such an activity.

- Plutchik's theory, which allows identifying eight basic and sixteen additional types of organizational vandalism, underlies the model of its emotional basis, developed by the study.

- When using this theoretical model of the emotional basis of employees' vandalism for preventing workplace destructive behavior, specialists in the field should consider specific factors of various organizational environments that could trigger vandal behavior. 
ПСИхОЛОГИЯ ТРУДА

\section{For citation}

Kruzhkova O. V., Deviatovskaia I. V., Vorobyeva I. V. Emotional Basis of Organizational Vandalism: A Theoretical Model. Rossiiskii psikhologicheskii zhurnal-Russian Psychological Journal, 2018, V. 15, no. 4, pp. 179-205 (in Russian). DOI: 10.21702/rpj.2018.4.8

Original manuscript received 30.09.2017

\section{Введение}

Активный ритм современной жизни изобилует событиями, переживаниями, стрессами, сопровождаемыми эмоциями, которые являются неотъемлемым компонентом переживаний. Такая высокая эмоциональная насыщенность проявляется и при выполнении профессиональной деятельности. В ходе реализации трудовых задач и при взаимодействии с коллегами возникают ситуации, когда приходится тем или иным образом подавлять или ограничивать свои эмоции. Профессиональные трудности и сложные ситуации сопровождаются индивидуальными переживаниями сотрудника, и как следствие, происходят существенные изменения в поведении персонала, выражающиеся в поиске новых тактик и стратегий поведения, позволяющих отреагировать интенсивные эмоции. Расширению спектра поведенческих стратегий взрослого человека способствуют также изменчивость современной социальной среды, ее динамизм, разнообразие и вариативность, ориентация на мультикультурализм и либерализацию общества [1, 2]. Событийная интенсификация зачастую приводит к разбалансированности ответного поведения личности, требуя оперативный выбор ответной поведенческой стратегии в ограниченный временной промежуток. В этом случае апробация новых, в том числе и деструктивных, форм поведения является результатом поиска потерянного равновесия через переживаемые эмоции [3] и их отреагирование. Однако поиск и освоение новых поведенческих форм зачастую проходят на грани девиации как зоны расширения поведенческого спектра личности [4] и/или регрессивного возврата к ранним (например, детским и подростковым, а также культурно примитивным) тактикам поведения [5]. Одной из таких форм поведения, связанного с вызовами внешней среды, выступает вандализм [6, 7, $8,9,10,11,12]$.

Традиционно считается, что вандализм как деструкция поведения встречается среди подростков и юношей $[6,10,13,14,15,16]$, однако и для взрослых людей характерно использование деструктивных действий с объектами среды, не являющимися их собственностью и без разрешительного санкционирования на указанные действия. В зарубежных исследованиях указывается, что хотя большинство задержанных за вандализм являются подростками, определенную долю среди правонарушителей составляют и лица старше 25 лет $[17,18,19]$. 
Особенностью вандализма взрослых является то, что его формы, как правило, носят менее демонстративный характер, но могут встречаться как в бытовых отношениях (поджоги собственности недоброжелателя, погромы в общественных местах и пр.), так и в организационном взаимодействии (мелкое вредительство и создание помех для деятельности коллег, халатное отношение к служебной информации и пр.). «Вульгарный» бытовой вандализм зачастую связан с асоциальным маргинальным образом жизни отдельных людей, в том числе бродяжничеством [20, 21], а также с нахождением человека в состоянии алкогольного или наркотического опьянения [22]. Однако именно вандализм на рабочем месте привлекает к себе наибольшее внимание, поскольку имеет гораздо более существенные последствия и широкое распространение среди сотрудников современных организаций.

Под организационным вандализмом, демонстрируемым сотрудниками в организации, понимается «социально-психологическое явление, характеризующееся несанкционированным изменением (порча, разрушение, деформация, преобразование и пр.) персоналом организационной среды (материальной, информационной, культурной), наносящим ущерб (экономический, экологический, социальный) организации» [см. 9, с. 153]. Вандализм, как и иное деструктивное отклонение, в организационной среде является добровольным поведением, которое нарушает значительные организационные нормы, тем самым угрожая благополучию организации и ее членов [23].

Организационный вандализм достаточно редко описывается как в специальной литературе, так и в открытых источниках. Причина этого явления кроется в нежелании подавляющего числа организаций разглашать факты деструктивного поведения своего персонала, поскольку это негативно влияет на их деловую репутацию. S. Cohen [24] указывает, что подобная практика «толерантного» отношения к вандализму взрослых весьма распространена в социуме. Также следует учитывать, что случаи организационного вандализма объяснимо скрываются и самими сотрудниками - субъектами вандализма, поэтому часто не классифицируются организацией как вандализм. До определенного момента организация готова не замечать деструктивные действия сотрудника, если «прибыль» от его основной деятельности превосходит ущерб от его деструктивного, в том числе и вандального, поведения [25]. Таким образом, организации сознательно попустительствуют мелким формам вандализма сотрудников, безнаказанность которых впоследствии может приводить к более значительным деструкциям организационного поведения и существенному ущербу для организации. Так, финансовые издержки организаций в Соединенных Штатах из-за краж, совершаемых персоналом, оцениваются в 50 миллиардов долларов в год [26]. 


\section{Теоретическое обоснование}

Можно отметить, что имеется несколько теорий происхождения вандализма (теория «разбитых окон» J. Q. Wilson и G. L. Kelling, теория напряженности R. Merton, теория удовольствия M. Csikszentmihalyi и R. Larsen, эстетическая теория V. L. Allen и D. B. Greenberger, теория самоконтроля T. Hirschi, теория справедливости J. D. Fisher и др.), и в большинстве из них упоминается эмоциональная основа его возникновения. Это актуально и для организационной среды, где сотрудник регулярно испытывает стресс из-за множества неблагоприятных факторов, которые вызывают самые различные эмоции, дестабилизирующие поведение человека. На наличие эмоциональной составляющей в совершении вандальных действий указывали S. Cohen [27], D. Canter [28], R. M. Baron [29], V. M. Weinmayr [30]. Мы предполагаем, что определенные эмоциональные состояния, переживаемые сотрудником, могут провоцировать его деструктивную активность в форме организационного вандализма. При этом конкретные эмоции будут вызывать вполне прогнозируемые мотивационные виды вандализма персонала. Как указывает Р. Плутчик, эмоции выступают в качестве некой цепи событий, необходимой для поддержания стабильности поведения. Эти цепи могут быть вызваны событиями в окружающей среде, связанными с другими людьми. В ходе когнитивной оценки и интерпретации данных средовых триггеров формируются определенные вегетативные изменения и эмоциональные реакции. В целом это подготавливает человека к действиям и демонстрации определенного поведения [31]. Подобная связь эмоций и поведения человека, выступающая одним из базовых положений эволюционной теории эмоций Р. Плутчика, позволяет нам описать эмоции как основу возникновения организационного вандализма персонала.

Согласно данной теории, эмоции позволяют человеку адаптироваться к окружающей среде, являясь своеобразным ответом на значимые жизненные ситуации и зачастую мотивируя человека к действию [32]. В контексте организационного вандализма именно изменения или напряжения в социальной среде организации, противоречия между ожиданиями сотрудника и реалиями организационной жизни (например, субъективное ощущение несправедливости) могут приводить к возникновению интенсивных эмоциональных реакций (гнева, обиды, страха и пр.), отреагируемых через деструктивную активность. Эмоции, являясь частью социально-регулируемого процесса [32], позволяют управлять социальной и материальной средой в жизнедеятельности человека. Злость, например, является средством запугивания и влияния на других, заставляя их делать то, что необходимо субъекту, побуждая человека к нападению или защите, вовлекая окружающих в конфликт. Однако это делает не сама эмоция, испытываемая человеком, а ее поведенческое выражение. Вандализм персонала на рабочем месте может рассматриваться 
с этих же позиций как поведенческое выражение отдельных эмоциональных состояний, призванное изменить или отрегулировать организационную среду для наибольшего комфорта жизнедеятельности человека в ней.

Впрочем, в основе организационного вандализма могут лежать весьма разнообразные эмоциональные состояния, которые специфицируют процесс совершения вандальных действий на рабочем месте, однако в целом их результат однозначно будет рассматриваться как урон для организации и деструкция ее деятельности и среды.

В указанной выше теории Р. Плутчика окружающая среда каждого организма (в том числе организационная среда для сотрудника) создает определенные общие проблемы, которые условно можно назвать «экзистенциальными кризисами», или «универсальными проблемами адаптации» всего живого [33]. И здесь эмоции выступают попытками организмов достичь контроля над этими явлениями с целью выживания. Таким образом, «эмоции - это ультраконсервативные эволюционные поведенческие адаптации, основанные на генетических кодировках, которые обеспечивают повышение шансов выживания организмов» [см. 31, р. 6].

Любая из четырех «универсальных проблем адаптации» имеет два эмоциональных и поведенческих варианта решения, представляющие собой, по мнению Р. Плутчика, биполярные факторы или оси, где разрушению, объединению, воспроизводству и ориентации противостоят защита, отторжение, лишение и исследование, как прототипы биологически адаптивного поведения, проявляющиеся на всех эволюционных уровнях (начиная от примитивнейших одноклеточных организмов и заканчивая человеком). Аналогично и соответственно прототипам поведения выделяются четыре пары антагонистичных базисных эмоций: гнев - страх, доверие - отвращение, радость - печаль, удивление - ожидание [32]. При этом указанные восемь базисных эмоций сгруппированы по принципу спектрального круга. Эмоции, находящиеся рядом (смежные) обладают некоторыми сходными характеристиками, но чем дальше по спектральному кругу находятся эмоции, тем больше они различаются между собой. В результате - противостоящие друг другу эмоции являются полярно противоположными. Это соотносится с идеей W. McDougall, который проводил параллель между эмоциями и цветами, написав, «что эмоции, как и цветовые ощущения, представляют бесконечно великое множество качеств, переходящих из одного в другое незаметными градиентами» [см. 34, р. 39].

\section{Результаты}

Опираясь на анализ литературных научных источников и существующих подходов к пониманию деструктивного поведения персонала [35, 36, 37], мы 
разработали теоретическую модель эмоциональной основы организационного вандализма. Данная модель объясняет происхождение отдельных мотивационных видов вандализма исходя из преобладания отдельных базовых эмоций или сочетания последних друг с другом. В основу визуального представления модели положен принцип спектрального круга, соответствующий модели эмоций Р. Плутчика. В результате смежно расположенные мотивационные виды вандализма обладают схожими по эмоциональным характеристикам чертами, а противостоящие - противоположными.

Описание мотивационных видов организационного вандализма в рамках предложенной модели позволяет отойти от стереотипного представления о доминации агрессивной составляющей при совершении деструктивных действий персоналом по отношению к среде организации. Градация эмоциональных состояний человека в ситуации трудовой деятельности многовариативна. И любое из них, если обладает достаточной степенью интенсивности при сопутствующих факторах-основах и факторах-триггерах [9], может быть причиной вандального поведения человека на рабочем месте.

Основываясь на ведущей роли эмоций в активации поведения, можно соотнести базисные эмоции и отдельные мотивационные виды вандализма персонала (таблица 1).

Описанные мотивационные виды вандализма характеризуются специфическими моделями поведения, которые инициируются определенными эмоциями (рисунок 1).

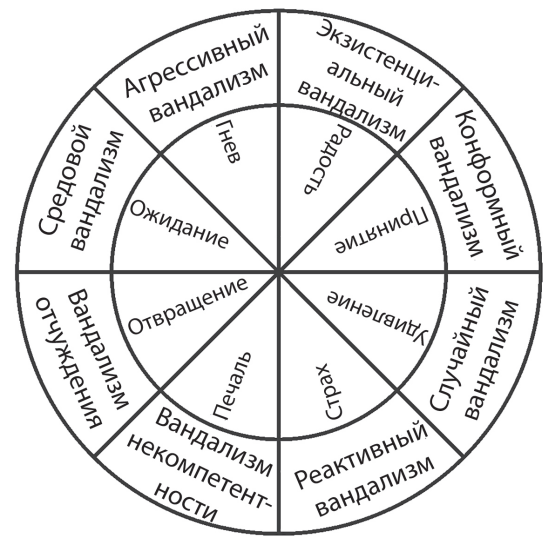

Рисунок 1. Первичные эмоции и мотивационные виды ванАализма персонала

Figure 1. Primary emotions and motivational types of employees' vandalism 


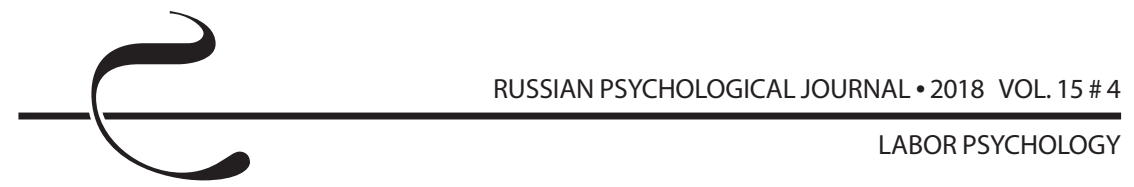

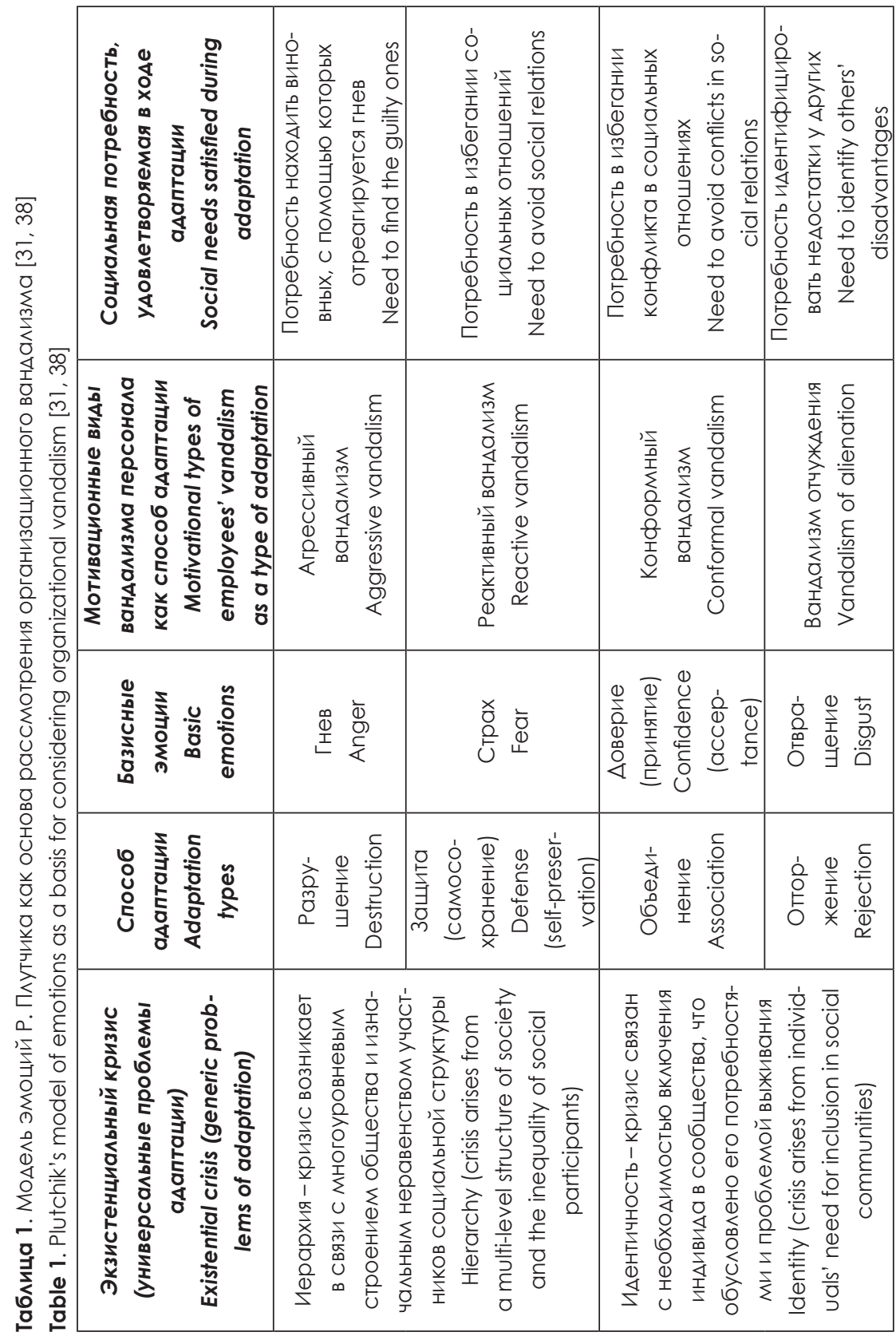




\begin{tabular}{|c|c|c|c|c|}
\hline 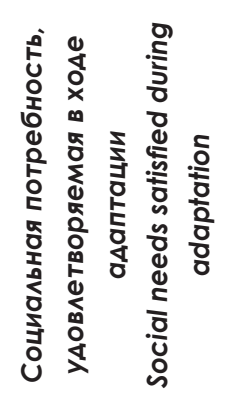 & 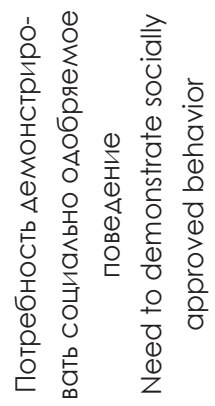 & 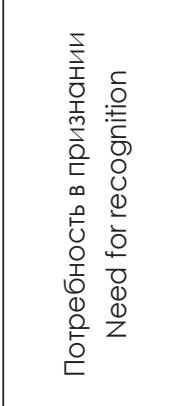 & 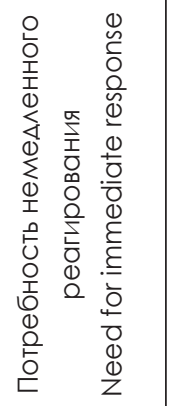 & 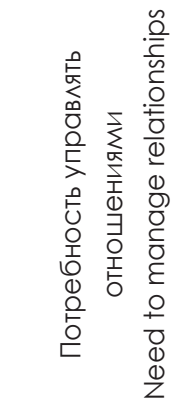 \\
\hline 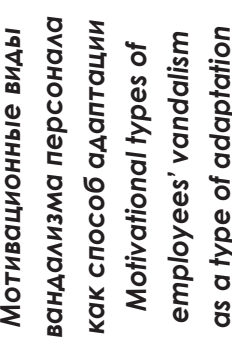 & 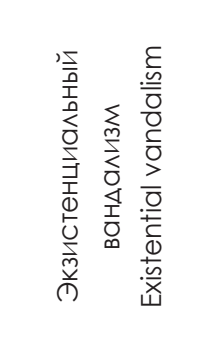 & 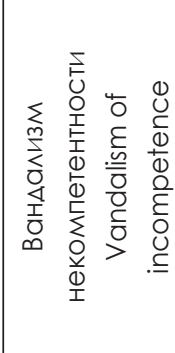 & 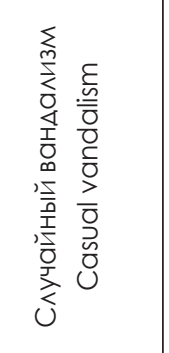 & 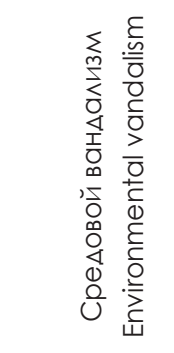 \\
\hline 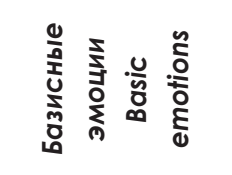 & 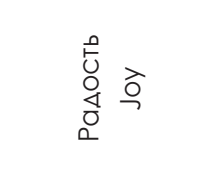 & 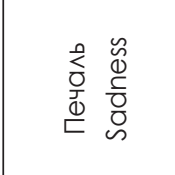 & 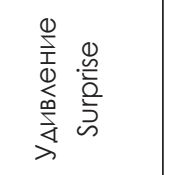 & 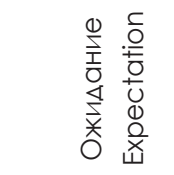 \\
\hline 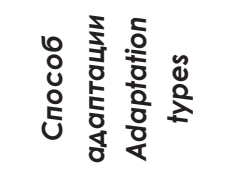 & 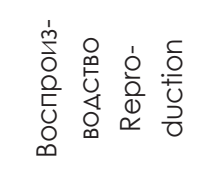 & 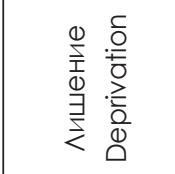 & 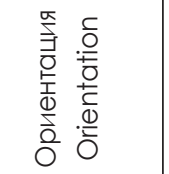 & 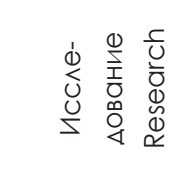 \\
\hline 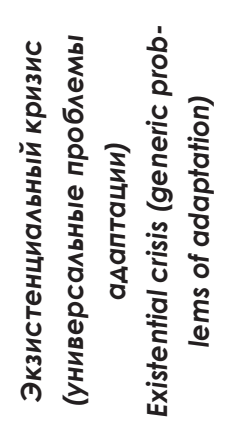 & 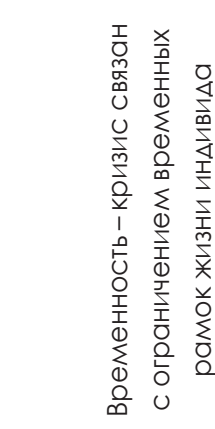 & 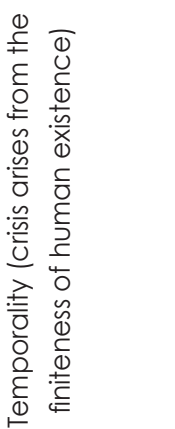 & 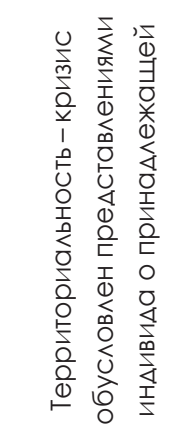 & 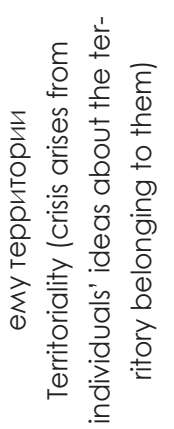 \\
\hline
\end{tabular}


Агрессивный вандализм. Данный вид вандализма реализуется как ответная реакция человека на негативное воздействие факторов организационной среды, вызывающих у него эмоцию гнева. Агрессия может принимать вид «горячей» реакции при восприятии провокации или реальной угрозы целостности субъекта (физической или психологической) [39]. Вместе с тем, это может быть и спланированная акция, осуществляемая контролируемым образом с заранее известной целью [40]. В то же время некоторые специалисты указывают, что прямая форма проявления агрессии (физическое насилие, нападения и пр.) в организации встречается не так уж часто, более вероятна косвенная агрессия, «тайный вред» [36] - вымещение негативных эмоций на объектах материальной и информационной среды организаций, приводящая к их повреждению или разрушению.

Реактивный вандализм. В основе подобного поведения лежит эмоция страха, когда вандальные действия выступают в форме защитной реакции на реальную или потенциальную внешнюю угрозу. В результате защитных действий или бездействия сотрудника, вызванных страхом (начальства, ситуации, оценки, последствий и пр.), причиняется существенный вред организационным ресурсам вследствие несвоевременного информирования (страх гонца, приносящего плохие известия), некачественного исполнения (страх оценки, приводящий к ошибкам в деятельности), моббинга (страх конкуренции со стороны другого сотрудника) и т. п.

Конформный вандализм. Данная форма вандальной активности сотрудника связана с реализацией групповых экспектаций по отношению к нему. Ради признания референтной группой (коллегами, «кликой») человек совершает деструктивные действия в организационной среде, причем они могут как совершаться совместно с группой (групповой моббинг), так и выполняться индивидуально, например, быть ритуалом инициации (принятия) в группу. Как правило, сотрудник здесь ожидает одобрения собственных деструктивных действий со стороны значимого окружения и в результате их реализации чувствует свою сопричастность к группе и единение с ее интересами.

Вандализм отчуждения. Проявляется как способ дистанцирования от организации, противопоставления своего личностного и профессионального пространства организационному, индивидуальных целей - коллективным. Так, Ö. Özer и коллеги указывают, что отчуждение сотрудника приводит к значительному нарушению психологического климата и организационного благополучия [41]. Человек переживает бессилие, бессмысленность своей деятельности в «чуждой» для него организации, в связи с чем результаты собственных деструктивных действий в ее среде также обесцениваются и становятся приемлемыми для него.

Экзистенциальный вандализм. Разрушение или преобразование объектов организационной среды в соответствии с волей отдельного сотрудника 
является общественной демонстрацией его власти над материальным и социальным пространством или ситуацией и вызывает у него чувство удовлетворения и радости. Это один из немногих видов вандализма, где авторство не скрывается, а публично объявляется. Исследования Л. С. Ватовой показали, что мотив самоутверждения, лежащий в основе подобных вандальных действий, наиболее свойственен тем людям, которые имеют претензию на лидерство в группе [6]. Подобное поведение характерно для «негативных» лидеров в организации и используется ими как тактика привлечения к себе внимания коллектива и создания оппозиционной коалиции.

Вандализм некомпетентности. Данный вид вандализма является следствием невозможности квалифицированной и качественной реализации профессиональной деятельности сотрудником в силу объективных обстоятельств (например, отсутствия опыта, необходимой компетентности и т. п.) при наличии обязательного условия ее выполнения. В этой ситуации человек переживает фрустрацию, вызванную ощущением предела собственных возможностей, что сопровождается эмоциональной угнетенностью, снижением самооценки и переживанием печали.

Случайный вандализм. Появляется как результат непреднамеренных действий сотрудника, когда он не может полностью спрогнозировать последствия собственной активности. Зачастую это продуцируется изменениями в организационной среде, попаданием в новые условия иной организации, где человеку приходится оперативно реагировать на незнакомые стимулы или быстро меняющуюся ситуацию. В связи с этим возможен регрессивный возврат и обращение к детским формам поведения, предполагающим непосредственность, игру, снижение уровня антиципации и ответственности.

Средовой вандализм. Как указывает А. T. Welford, эргономика мест и ее несоответствие потребностям человека часто выступают причиной вандального поведения [42]. Исходя из этого, из-за низкой эргономичности организационной среды в целом, или рабочего места в частности, у сотрудника может возникать стремление изменения отдельных элементов среды ради персонального комфорта или безопасности. Основная цель подобного, деструктивного для организации, поведения персонала субъективно воспринимается сотрудником как просоциальная, а свои действия он позиционирует как преобразование среды организации ради собственного или общественного удобства (проделанные лазы в заборах, сломанные замки для облегченного доступа в помещения и пр.). Ожидание будущих преференций в виде повышения субъективного удобства от результатов деструктивных действий сотрудника является эмоциональной основой и мотиватором воплощения вандальной деятельности.

В то же время в жизни мы испытываем не только «чистые» базисные эмоции, но и их производные, т. е. более сложносоставные эмоциональные реакции. 


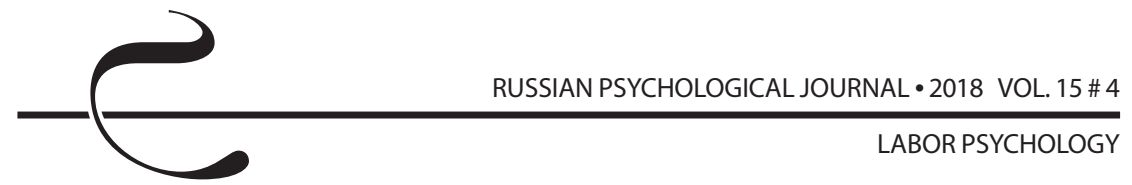

Если посмотреть на рисунок 1, то становится очевидно, что любая смежная пара первичных эмоций могла бы быть объединена с целью формирования промежуточного звена - смешанной эмоции, так же, как и любые два смежных цвета в спектре формируют промежуточный оттенок. Смесь из любых двух первичных выборов может называться диадой. При этом данные диады могут быть сформированы различными способами. Если смешиваются две смежные первичные эмоции, то данная комбинация может называться первичной диадой. Смеси двух первичных эмоций, которые располагаются на круге через одну, могут называться вторичными диадами, в то время как смеси первичных эмоций, которые уже расположены на круге через две - третичными диадами [33]. Руководствуясь этим принципом, можно получить расширенный спектр мотивационных видов организационного вандализма (рисунок 2), которые объединены в обобщенную модель.

\section{Мотивачионные виды вандализма, образованные диадами смежных эмочий}

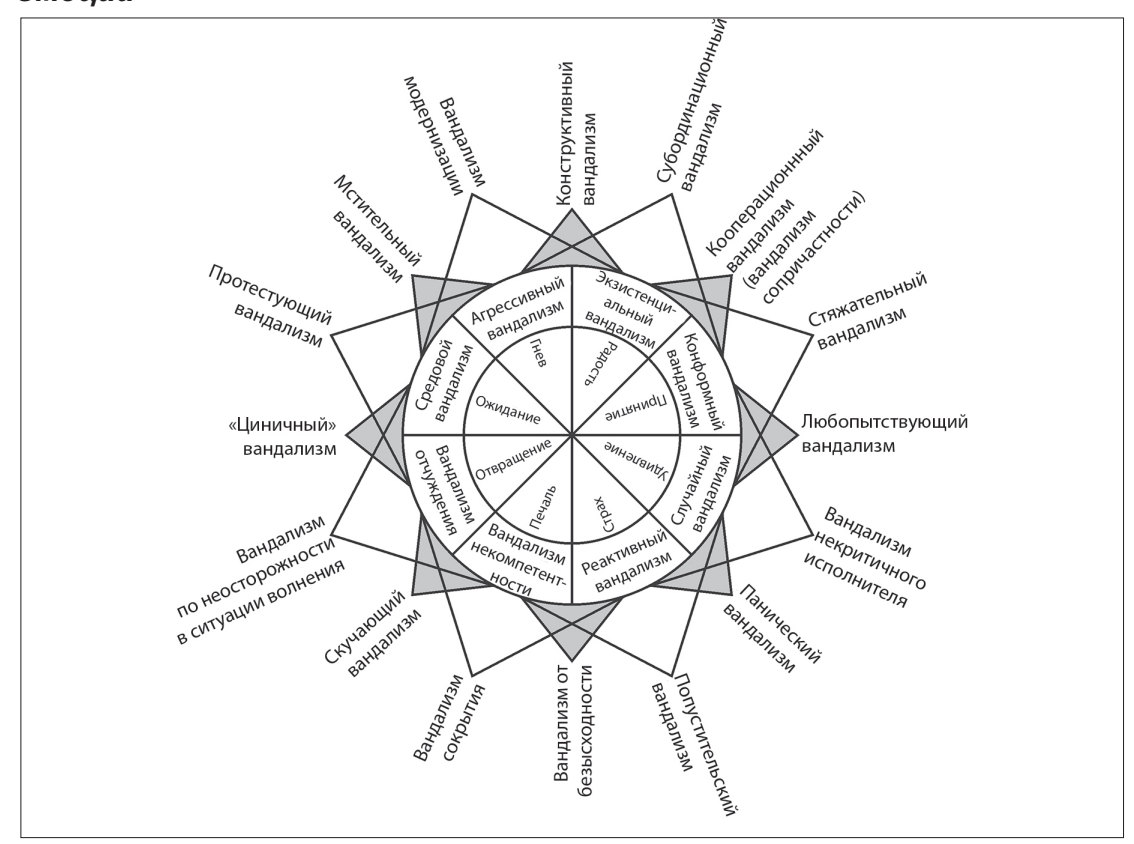

Рисунок 2. Молель эмоциональной основы МотивационныХ виАОв организационного ванАализма

Figure 2. Model of emotional basis of motivational types of organizational vandalism 
Конкурентный вандализм (гнев + радость = гордость) характерен для ситуации скрытого или явного соперничества между сотрудниками. В этом случае агрессия в форме вандализма по отношению к предметам и результатам деятельности соперника позволяет снизить его ресурсы и приобрести конкурентное преимущество перед ним субъекту вандализма.

Кооперационный вандализм, или вандализм сопричастности (радость + принятие = любовь, дружелюбие), возникает как стремление быть включенным в референтную группу, может реализовываться в форме «ритуала инициации» для вхождения/принятия в закрытое сообщество внутри социальной системы организации. В результате сотрудником осознанно наносится ущерб среде организации, но воспринимается это как демонстрация его возможностей и, при одобрении группы, личностно оценивается как позитивное поведение.

Любопытствующий вандализм (принятие + удивление = любопытство) происходит из-за чрезмерной любознательности и «разрушительного экспериментаторства» с объектами организационной среды. В этом случае целью разрушения является познание. Д. Кантер показывает, что стремление понять и разобраться с тем, как устроен и функционирует какой-либо объект, может приводить к направленно вандальной активности человека [28]. Это может быть также экстраполировано с материальных объектов на социальные системы, когда «изучается» прочность социальных связей и межличностных отношений, устойчивость социальных норм, авторитета руководителя и пр.

Панический вандализм (удивление + страх = смятение, трепет) возникает как следствие высокой стрессогенности в производственных ситуациях, когда низкая прогностичность в отношении происходящего вызывает у сотрудника (субъекта вандализма) страх последствий, инициирует избегающие реакции, суетливость, необдуманные действия, которые могут приводить к поломке рабочего оборудования, повреждению организационной среды.

Вандализм от безысходности (страх + печаль = отчаяние) происходит вследствие фрустрационных состояний сотрудников, когда возникает ощущение отсутствия выхода из затруднительного положения, а вандализм является единственным осознаваемым человеком способом решения сложившейся ситуации.

Скучающий вандализм (печаль + отвращение = страдание): мотивом выступает поиск новых впечатлений, острых ощущений, связанных с запретностью и опасностью [27], которые позволят отвлечься от рутинных обязанностей. Безделье, скука, неумение занять себя, поиск развлечений часто бывают связаны со скудностью информационного фона, незанятостью человека работой [6]. M. Csikszentmihalyi, R. Larsen в рамках описания модели удовольствия указывают, что несоответствие возможностей человека и средовых вызовов, эмоциональное состояние скуки и однообразия, а также отсутствие четкой системы правил приводят к возникновению у него чувства неудовлетворенности. Это, возможно, 
будет компенсироваться через альтернативную деструктивную деятельность, которая принесет необходимое человеку удовольствие [43].

«Циничный» вандализм (отвращение + ожидание = цинизм) проявляется у сотрудников, разочарованных в социальных механизмах и авторитетах, проявляющих недоверие к организации, ее целям, и несогласных с ее организационной культурой вследствие собственного накопленного отрицательного опыта и невозможности открытого выражения негативных чувств. В этом случае вандализм выступает как реакция на резкие изменения в организации, например, в ситуации инновационной деятельности, как результат разочарования в новых целях, из-за разрыва между идеалами, заявленными как новая ценность, и несоответствующей им реальностью [44]. J. Schilling, описывая мультифакторную природу циничного поведения сотрудников (нарушение психологического контракта между работником и работодателем, дисбаланс вклада и результата, отсутствие возможности участвовать в принятии решений и т. д.), подчеркивает, что значимую роль в поведении организационного цинизма играет руководитель организации, становясь негативным образцом для подражания или демонстрируя собственное деструктивное поведение в общении с сотрудниками [45].

Мстительный вандализм (ожидание + гнев = месть). В целом мотив мести можно рассматривать как определенные негативистские действия. D. Canter считает, что мотив мести возникает как ответ обществу или его отдельным представителям за ущемление каких-то интересов субъекта вандализма [28]. Например, граффити, влекущие порчу общественного или частного имущества (что само по себе является нарушением социальных запретов), представляют собой относительно безопасный для индивида способ заявить о своей оппозиции закону или другим социальным институтам. S. Cohen также описывает данный вид вандализма как мщение, когда разрушение происходит в ответ на обиду или оскорбление. Специфической особенностью здесь выступает то, что разрушение является отлаженным ответом на действия противной стороны и совершается анонимно. Обида может не иметь под собой реальных оснований, быть воображаемой. Также объект разрушения может напрямую не являться собственностью человека или организации, против которых выступает субъект вандализма, а быть связан с ними лишь косвенно, символически, опосредованно. Эмоциональный «выплеск» и совершаемые разрушения позволяют снять накопившееся напряжение по принципу замещения как механизма психологической защиты [27].

\section{Мотивационные виды вандализма, образованные диадами эмоций «через одну»}

Субординационный вандализм (гнев + принятие = господство) характерен для ситуаций, когда действия его субъекта опосредованы организационной 
иерархией. При этом вандальная активность инициируется гневом и необходимостью принять ситуацию либо человека (руководителя, подчиненного, коллегу, клиента и т. д.), что приводит к переживанию неограниченной власти и господства, осознанию возможности оказывать влияние. Часто субординационный вандализм проявляется как моббинг на рабочем месте [46] или боссинг, если субъектом вандализма оказывается руководитель [47].

Стяжательный вандализм (радость + удивление = наслаждение) - это вандализм, совершаемый ради получения выгоды, приобретения чего-либо. Его основным мотивом является материальная выгода, а разрушение каких-либо объектов организационной собственности выступает как сопутствующее последствие достижения цели приобретения. Как указывает S. Cohen, данный вид вандализма является некой разновидностью кражи [27]. При этом часто вандалами изымаются отдельные части оборудования, информационных стендов, декора помещений, иногда в целях коллекционирования, инсталляций, что в итоге нарушает целостный облик организационной среды и может приводить к аварийным ситуациям на производстве.

Вандализм некритичного исполнителя (принятие + страх = покорность, скромность). Исполнительность понимается в психологических исследованиях как подчинение субъекта требованиям и командам других лиц, процесс реализации поставленных ими целей и задач. Экстернальная природа исполнительного действия, а именно постановка цели не самостоятельно, а извне, способствует некритичному восприятию исполнителем окружающей действительности, «слепому» исполнению приказов и поручений, с руководствованием мотивом избегания неудач [48]. В таком случае страх неудачи, покорность при исполнении, отсутствие желания разобраться в ситуации, и, при необходимости, проявить ответственность или инициативу, скромность, а иногда и внешняя конформность, - в совокупности могут нанести ущерб организации и ее среде.

Попустительский вандализм (удивление + печаль = замешательство, разочарование). Данный вид вандализма вызван разочарованием, как связанным с несбывшимися ожиданиями, планами, так и разочарованием в себе, других, организации. Отрицательный или угнетенный эмоциональный фон способствует развитию чувства, что «все уже потеряно», равнодушию к происходящему и действиям сотрудников, наносящим ущерб организации. При таком попустительстве вандальное поведение коллег и подчиненных принимает более серьезные и разрушительные масштабы.

Вандализм сокрытия (страх + отвращение = стыд, ханжество). Как правило, данный вид вандализма проявляется в ситуации, когда страх оказывает влияние или даже определяет выбор стратегии поведения сотрудника, регуляции ответственного поведения личности [49]. В психологии управления 
оперируют понятием «организационный страх», например, страх потери работы, страх не справиться с работой, страх допустить ошибку, потерять собственное Я и др. [50]. Так, страх не справиться с работой или допустить ошибку приводит к сильной эмоциональной напряженности, а страх принять ответственность за свои действия провоцирует тревожность и неудовлетворенность собой, т. к. в ситуации неуспеха повышается риск быть отверженным коллективом или профессиональным сообществом, потерять место работы, должность и т.д. Попытка избежать негативных последствий или справиться с ними в реальности побуждает сотрудника скрывать как результаты своих действий, так и свой страх под маской ханжества.

Вандализм по неосторожности в ситуации волнения (печаль + ожидание = пессимизм). Оптимальный уровень волнения позволяет человеку мобилизовать силы и ресурсы, чтобы справиться с предстоящей сложной ситуацией. Вместе с тем, очень сильное волнение и отсутствие навыков самоконтроля в сочетании с неадекватными ожиданиями от предстоящего события являются основой для проявления вандализма по неосторожности в ситуации волнения. Например, волнение в первый день на рабочем месте или перед новым ответственным заданием может привести к неуверенности в себе, акцентированию на негативных качествах, обстоятельствах, чертах. Все это усиливает волнение и создает основу для совершения ошибок по неосторожности, невнимательности, наносящих ущерб организации.

Протестующий вандализм (отвращение + гнев = пренебрежение, омерзение, негодование, презрение, ненависть, возмущение, враждебность). Протест против социальных и культурных норм взрослого мира довольно часто характеризует поведение подростков. В то же время, данный вид вандализма вполне может быть присущ человеку, вышедшему за пределы подросткового возраста - представителю оппозиционных субкультур или человеку, сочувствующему какой-либо политической партии, общественной организации и совершающему вандальные акты по отношению к собственности их оппонентов, или человеку, обиженному на общество или отдельных его представителей и демонстрирующему свою обиду через вандальные действия и т. п. Подобное же предполагает и H. E. Roos, связывая вандализм с ущемлением стремления человека к гедонизму, когда все предметы, воспринимаемые как препятствие для получения удовольствия, вызывают протест. Таким образом, вандализм - это разрушение источников запрета [51]. R. M. Baron и J. D. Fisher в рамках теории взаимодействия субъективной несправедливости и уровня контроля утверждали, что глубинным мотивом вандализма является восстановление справедливости, попранной в результате перманентного нарушения другими людьми правил общественного бытия или не подтвердившихся экспектаций субъекта [29]. Результаты исследования организационной справедливости, 
проведенного D. R. Bobocel, доказывают, что восприятие своей организации как справедливого субъекта у одних сотрудников может способствовать конструктивным ответам на несправедливые события в ней, у других же подавлять деструктивные ответы и мстительные намерения [52].

Вандализм модернизации (ожидание + радость = оптимизм, храбрость, надежда, тщеславие). Необходимо отметить, что положительные эмоции также могут выступать основой вандального поведения персонала. Так, оптимизм и уверенность в результате, надежда на лучший вариант развития событий, ожидание, что действия обязательно обеспечат достижение цели, способны, особенно при их необоснованно высоком уровне выраженности, нанести ущерб собственности организации или ее репутации. Например, тщеславное стремление непременно хорошо выглядеть в глазах окружающих и получать подтверждение своей успешности и уникальности приводят к неадекватной оценке рисков и, как следствие, получению результата, не соответствующего ожиданиям. Кроме того, нарушение организационных норм может приводить к креативным результатам [25].

\section{Обсуждение результатов}

Таким образом, проведенное исследование показывает, что организационный вандализм может иметь достаточно дифференцированную эмоциональную основу, которая в свою очередь инициирует иррациональную, нерефлексируемую форму взаимодействия человека с окружающей его средой. Необходимо отметить, что разрушительные действия выбираются сотрудником не всегда, но при лимитировании времени и ресурсов, определенной личностной склонности или наличии опыта подобной активности [9] человеку «проще» отреагировать эмоциональное напряжение деструктивной формой поведения, в том числе вандальными действиями. При этом личный успешный опыт организационного вандализма способствует как закреплению такой поведенческой девиации и ее систематическому использованию, так и формированию установки на ее «нормативность». Эффективность вандализма при решении производственных ситуаций, возможность оперативного получения результатов от своих действий трансформируют организационный вандализм в способ совладания с эмоционально напряженными ситуациями для конкретного сотрудника.

Сформированная модель эмоциональной основы мотивационных видов организационного вандализма демонстрирует многообразие эмоциональных состояний, которые могут приводить к деструктивному поведению человека в организации. В целом представленная модель является одним из вариантов разработки теоретической основы для объяснения «психологических механизмов возникновения контр-продуктивного поведения» [см. 35, с. 54] 


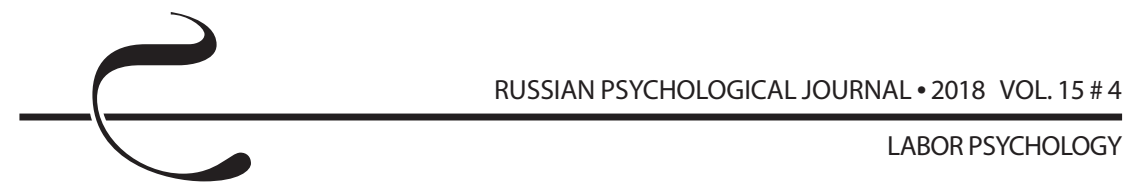

работников, что созвучно с методологическими вопросами в области психологии деструктивной активности персонала на рабочем месте [35].

Резюмируя вышеизложенное, отметим следующие результаты представленного теоретического исследования эмоциональной основы организационного вандализма персонала:

1. В среде организации возможна деструктивная активность персонала, выражающаяся, в том числе, в виде вандальных действий по отношению к объектам окружающего пространства. Вероятнее всего, инициируется данная девиация определенными эмоциональными состояниями, которые вызываются триггерами организационной среды.

2. Для объяснения механизмов, инициирующих деструктивное поведение персонала организации, была использована эволюционная теория эмоций Р. Плутчика, в рамках которой возможно не только выделение базисной эмоции, провоцирующей у человека вандальную активность, но и описание стратегии адаптации и основных потребностей, удовлетворяемых сотрудником в процессе приспособления к окружающей среде организации.

3. Описана теоретическая модель, где соотнесены базисные эмоции (в соответствии с теорией Р. Плутчика) и отдельные виды вандализма персонала, такие как агрессивный вандализм, реактивный вандализм, конформный вандализм, вандализм отчуждения, экзистенциальный вандализм, вандализм некомпетентности, случайный вандализм, средовой вандализм. А также описаны дополнительные шестнадцать видов организационного вандализма, где основой выступают сложносоставные эмоциональные состояния.

4. Предложенная модель эмоциональной основы организационного вандализма для применения в практике управления организационным поведением нуждается в расширенной эмпирической проверке в связи с необходимостью обязательного учета субъективных факторов, связанных с индивидуальным опытом человека, его характерологическими особенностями, актуальными эмоциональными состояниями и пр. Однако важно понимать, что эмоционально опосредованное поведение, в том числе носящее признаки вандализма, не является случайным, бессмысленным, избыточным, оно всегда напрямую соотносится с импульсным событием, которое стоит в пусковой комплексной цепочке первым [31], т. е. с явлениями материальной, информационной и социальной среды самой организации. Вследствие этого эмпирическое исследование эмоциональной основы вандализма сотрудников должно предполагать учет факторов внутренней среды организации.

\section{Благодарности}

Исследование выполнено при поддержке Российского фонда фундаментальных исследований (Российского гуманитарного научного фонда), проект 17-06-00819. 
ПСИхОЛОГИЯ ТРУДА

\section{Acknowledgments}

Supported by the Russian Foundation for Basic Research (Russian Humanitarian Science Foundation), project 17-06-00819.

\section{Литература}

1. Семенова Ю. А. Формирование гражданской идентичности в условиях современного российского общества // Вестник Челябинского государственного университета. 2010. № 1. С. 104-108.

2. Симонова И. А. Поиски методологических оснований социального серфинга в исследованиях молодежи // Педагогическое образование в России. 2016. № 12. С. 238-243.

3. Plutchik R. The Nature of Emotions: Human emotions have deep evolutionary roots, a fact that may explain their complexity and provide tools for clinical practice // American Scientist. 2001. Vol. 89, № 4. P. 344-350. URL: http:// www.jstor.org/stable/27857503?seq=1\#page scan tab contents (дата обращения: 14.02.2018).

4. Осипова О. С. Девиантное поведение: благо или зло? // Социологические исследования. 1998. № 9. С. 106-109. URL: http://ecsocman.hse. ru/data/311/688/1217/020.OSSIPOVA.pdf (дата обращения: 14.02.2018).

5. Корелкин Е. Н. Проблемы трансформации системы профилактики в условиях социокультурного кризиса // Вестник Адыгейского государственного университета. Серия 1:Регионоведение: философия, история, социология, юриспруденция, политология, культурология. 2012. № 4 (108). С. 132-136.

6. Ватова Л. С. Социально-психологические основания молодежного вандализма и его профилактика. М.: Народное образование; Изд-во МПСИ, 2007. 298 с.

7. Гурова О. В. Школьный графический вандализм как конфликт между личностью и средой // Конфликтогенность современности / отв. ред. Л. А. Максимова. Екатеринбург: Изд-во УрГПУ, 2014. С. 49-65.

8. Клюев Р. В. Внутренние и внешние факторы экономического риска промышленного предприятия // Инструменты и механизмы современного инновационного развития: Сборник статей Международной научно-практической конференции. Ч. 1. Уфа: Аэтерна, 2016. С. 174-177.

9. Кружкова О. В., Девятовская И. В. Организационный вандализм: к проблеме деструктивного поведения персонала // Сибирский психологический журнал. 2017. № 63. C. 150-169. DOI: 10.17223/17267080/63/11

10. Кузнецова И. А., Попов В. А. Зарубежные исследования молодежного вандализма // Педагогика. 1997. № 6. С. 111-114.

11. Скороходова А. С. Вандализм // Социологический журнал. 1999. № 3-4. C. 49-67. 
12. Goldstein A. P. The Psychology of Vandalism. Boston, MA: Springer, 1996. 296 p. DOI: $10.1007 / 978-1-4899-0176-7$

13. Vorobyeva I. V., Kruzhkova O. V., Krivoshchekova M. S. The genesis of vandalism: From childhood to adolescence // Psychology in Russia: State of the Art. 2015. Vol. 8, № 1. P. 139-156. DOI: 10.11621/pir.2015.0112

14. Elliott D. S., Huizinga D., Menard S. Multiple Problem Youth: Delinquency, Substance Use, and Mental Health Problem. New York: Springer-Verlag, 1989. 226 p. DOI: $10.1007 / 978-1-4613-9637-6$

15. Le Blanc M., Fréshette M. Male Criminal Activity from Childhood Through Youth. New York: Springer-Verlag, 1988. 228 p. DOI: $10.1007 / 978-1-4612-3570-5$

16. Mawby R. I. Burglary. Devon, UK: Willan Publishing, 2001. 213 p.

17. United States Bureau of the Census: Statistical Abstract of the United States. 117th ed. Washington, DC: Hoovers Inc, 1997. 1022 p.

18. Kube E., Schuster L. Le vandalisme en milieu urbain: importance, portée et contexte du phenomena: mesures possibles de prévention. Strasbourg: Comité Européen pour les Problèmes Criminels, 1984. 24 p.

19. Lorenz M. Vandalismus als Alltagsphänomen. Bonn: Bundeszentrale für Politische Bildung, 2012. 157 p.

20. Stuart G. Conflict and homeless youth // Youth Studies Australia. 1994. Vol. 13, № 2. P. 27-30.

21. Tavecchio L. W. C. Moral Judgement and Delinquency in Homeless Youth // Journal of Moral Education. 2010.Vol. 28, № 1.P.63-79. DOI: 10.1080/030572499103313

22. Омаев Б. Х. Понятие вандализма и личностные особенности вандалов // Образование и право. 2013. № 5 (45) - 6 (46). С. 168-173.

23. Robinson S. L., Bennett R. J. A Typology of Deviant Workplace Behaviors: a Multidimensional Scaling Study //The Academy of Management Journal. 1995. Vol. 38, № 2. P. 555-572. DOI: 10.2307/256693

24. Cohen S. Sociological approaches to vandalism //Vandalism, behaviour and motivations / C. Levy-Leboyer (Ed.). Amsterdam; New York; Oxford: North Holland, 1984. P. 51-62.

25. Levy T., Tziner A. When destructive deviance in the workplace becomes a liability: a decisional behavioral model // Quality and Quantity. 2011. Vol. 45, Issue 1. P. 233-239. DOI: 10.1007/s11135-009-9277-0

26. Coffin B. Breaking the Silence on White Collar Crime // Risk Management. 2003. Vol. 50, № 8. P. 6. URL: https://www.questia.com/magazine/1G1-107762284/ breaking-the-silence-on-white-collar-crime (дата обращения: 14.02.2018).

27. Cohen S. Property Destruction: Motives and Meanings // Vandalism / C. Ward (Ed.). London: The Architectural Press, 1973. P. 23-53.

28. Canter D. V. Fires and Human Behavior. New York: John Wiley and Sons Ltd, 1980. 356 p. 
29. Baron R. M., Fisher J.D. The equity-control model of vandalism: a refinement // Vandalism, behaviour and motivations / C. Levy-Leboyer (Ed.). Amsterdam; New York; Oxford: North Holland, 1984. P. 63-76.

30. Weinmayr V. M. Vandalism by design: A critique // Landscape Architecture. 1969. Vol. 59. P. 286.

31. Plutchik R. Emotion: A Psychoevolutionary Synthesis. New York: Harper \& Row, 1980. 440 p.

32. Plutchik R. The measurement of emotions // Acta Neuropsychiatrica. 1997. Vol. 9, Issue 2. P. 58-60. DOI: $10.1017 /$ S0924270800036802

33. Plutchik R. The Emotions: Facts, Theories and a New Model. New York: Random House, 1962. 232 p.

34. McDougall W. An Introduction to Social Psychology. 14th ed. Boston, MA, US: John W Luce \& Company, 1921. 410 p.

35. Гулевич О. А. Контр-продуктивная активность в организации: определение, виды, факторы // Организационная психология. 2013. Т. 3, № 4. C. 49-58.

36. Kaukiainen A., Salmivalli C., Björkqvist K., Österman K., Lahtinen A., Kostamo A., Lagerspetz $K$. Overt and covert aggression in work settings in relation to the subjective well-being of employees // Aggressive Behaviour. 2001. Vol. 27, № 5. P. 360-371. DOI: 10.1002/ab.1021

37. Pietersen C. A Diagnostic Approach To Measuring And Managing Workplace Aggression // SA Journal of Human Resource Management. 2005. Vol. 3, № 1. P. 1-5. DOI: $10.4102 /$ sajhrm.v3i1.52

38. Кружкова О. В., Девятовская И. В. Психологические аспекты выделения эмоциональной основы организационного вандализма // Фундаментальные и прикладные исследования в современной психологии: результаты и перспективы развития / отв. ред. А. Л. Журавлев, В. А. Кольцова. М.: Изд-во Института психологии РАН, 2017. С. 1839-1846.

39. Ortega Escobar J., Alcázar Córcoles M. T. Neurobiology of aggression and violence [Neurobiología de la agresión y la violencia] // Anuario de Psicología Jurídica. 2016. Vol. 26, № 1. P. 60-69. DOI: 10.1016/j.apj.2016.03.001

40. Rosell D. R., Siever L. J. The neurobiology of aggression and violence // CNS Spectrums. 2015. Vol. 20, Special Issue 3. P. 254-279. DOI: $10.1017 /$ S109285291500019X

41. Özer Ö., Uğurluoğlu Ö., Saygılı M., Sonğur C. The impact of work alienation on organizational health: A field study in health sector // International Journal of Healthcare Management. 2017. DOI: 10.1080/20479700.2017.1312804

42. Welford A. T. Ergonomics: Where Have We Been and Where Are We Going: I // Ergonomics. 1976. Vol. 19, Issue 3. P. 275-286. DOI: 10.1080/ $\underline{00140137608931543}$ 


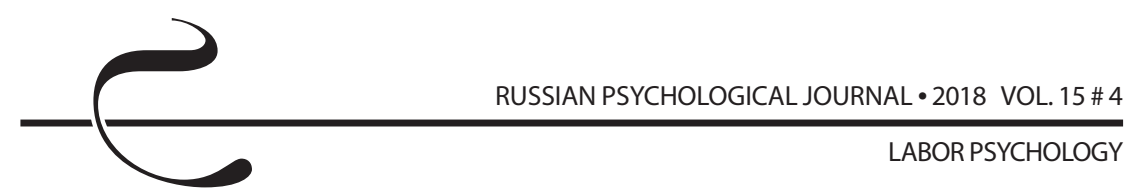

43. Csikszentmihalyi M., Larsen R. Intrinsic Rewards in School Crime // Applications of Flow in Human Development and Education. Dordrecht: Springer, 2014. P. 271-284. DOI: $10.1007 / 978-94-017-9094-914$

44. Гудков Л. Д. Перерождения «советского человека» (об одном исследовательском проекте Левада-центра) // Одиссей: Человек в истории. 2007. № 1. C. 398.

45. Schilling J. Organisationaler Zynismus als Herausforderung für Führungskräfte: Umgang mit destruktiven Einstellungen von Mitarbeitern // Herausforderung Führung - führen wollen, führen können, schwierige Situationen meistern / A. Gourmelon (Hrsg.). Heidelberg: Rehm, 2016. P. 21-36.

46. Zábrodská K., Květon P. Šikana na pracovišti v prostředí českých univerzit: výskyt, formy a organizač ní souvislosti // Sociologický časopis / Czech Sociological Review. 2012. Vol. 48, № 4. P. 641-668.

47. Momand H. Mobbing in der Arbeitswelt: Ursachen, Folgen und mögliche Lösungsansätze für ein verbessertes Arbeitsklima. Hamburg: Diplomica Verlag, 2011.207 p.

48. Прядеин В. П. Психолого-педагогические и социальные аспекты исполнительности // Педагогическое образование в России. 2015. № 9. С. 65-71.

49. Ярушкин Н. Н., Сатонина Н. Н. Социальный страх как регулятор ответственного поведения личности // Вестник Самарской гуманитарной академии. Серия «Психология». 2007. № 1. С. 78-84.

50. Карпов А. В. Психология менеджмента:Учебное пособие. М.: Гардарики, 2005. $584 \mathrm{C}$.

51. Roos H.-E. Vandalism as a Symbolic Act in Free Zones //Vandalism: Research, Prevention and Social Policy / C. Harriet H., J. Darryll J., \& B. Martha H. (Eds.). Seattle: US Dept. of Agruculture / Pacific Northwest Research Station and University of Washington, 1992. P. 71-87. URL: http://portal.research.lu.se/ portal/files/5546900/802127.pdf (дата обращения: 14.02.2018).

52. Bobocel D. R. Coping with unfair events constructively or destructively: The effects of overall justice and self-other orientation // Journal of Applied Psychology. 2013. Vol. 98 (5). P. 720-731. DOI: $10.1037 / a 0032857$

\section{References}

1. Semenova Yu. A. Formation of civil identity in modern Russian society. Vestnik Chelyabinskogo gosudarstvennogo universiteta-Bulletin of Chelyabinsk State University, 2010, no. 1, pp. 104-108 (in Russian).

2. Simonova I. A. Searching for methodological foundations of social surfing in youth research. Pedagogicheskoe obrazovanie v Rossii - Pedagogical Education in Russia, 2016, no. 12, pp. 238-243 (in Russian). 
3. Plutchik R. The Nature of Emotions: Human emotions have deep evolutionary roots, a fact that may explain their complexity and provide tools for clinical practice. American Scientist, 2001, V. 89, no. 4, pp. 344-350. Available at: http://www.jstor.org/stable/27857503?seq=1\#page_scan_tab_contents (Accessed 14 February 2018).

4. Osipova O. S. Deviant behavior: good or evil? Sociological Studies, 1998, no. 9, pp. 106-109 (in Russian). Available at: http://ecsocman.hse.ru/ data/311/688/1217/020.0SSIPOVA.pdf (Accessed 14 February 2018).

5. Korelkin E. N. Transformation of the system of prevention in times of sociocultural crisis. Vestnik Adygeiskogo gosudarstvennogo universiteta. Seriya 1: Regionovedenie: filosofiya, istoriya, sotsiologiya, yurisprudentsiya, politologiya, kul'turologiya - Bulletin of the Adyghe State University, the series "Region Studies: Philosophy, History, Sociology, Jurisprudence, Political Sciences and Culturology", 2012, no. 4 (108), pp. 132-136 (in Russian).

6. Vatova L. S. Sotsial'no-psikhologicheskie osnovaniya molodezhnogo vandalizma i ego profilaktika [Socio-psychological foundations for vandalism among youth and its prevention]. Moscow, Narodnoe obrazovanie Publ., 2007.298 p.

7. Gurova O. V. School graphic vandalism as a conflict between an individual and the environment. In: L. A. Maksimova (ed.) Konfliktogennost' sovremennosti [Conflictogenity nowadays]. Ekaterinburg, Ural State Pedagogical University, 2014, pp. 49-65.

8. Klyuev R. V. Vnutrennie i vneshnie faktory ekonomicheskogo riska promyshlennogo predpriyatiya [Internal and external factors for economic risks at industrial enterprises]. Sbornik statei Mezhdunarodnoi nauchno-prakticheskoi konferentsii "Instrumenty imekhanizmysovremennogo innovatsionnogo razvitiya" [Proc. International Theoretical and Practical Conference"Tools and mechanisms of modern innovative development: Part 1"]. Ufa, Aeterna Publ., 2016, pp. 174-177.

9. Kruzhkova O.V., Devyatovskaya I. V. Organizational vandalism: On the issue of employees' destructive behavior. Sibirskii psikhologicheskii zhurnal Siberian Journal of Psychology, 2017, no. 63, pp. 150-169 (in Russian). DOI: $\underline{10.17223 / 17267080 / 63 / 11}$

10. Kuznetsova I. A., Popov V. A. Western studies of vandalism among youth. Pedagogika - Pedagogy, 1997, no. 6, pp. 111-114 (in Russian).

11. Skorokhodova A. S. Vandalism. Sotsiologicheskii zhurnal - Sociological Journal, 1999, no. 3-4, pp. 49-67 (in Russian).

12. Goldstein A. P. The psychology of vandalism. Boston, MA, Springer, 1996. 296 p. DOI: $10.1007 / 978-1-4899-0176-7$

13. Vorobyeva I. V., Kruzhkova O. V., Krivoshchekova M. S. The genesis of vandalism: From childhood to adolescence. Psychology in Russia: State of the Art, 2015, V. 8, no. 1, pp. 139-156. DOI: 10.11621/pir.2015.0112 
14. Elliott D. S., Huizinga D., Menard S. Multiple problem youth: Delinquency, substance use, and mental health problem. New York, Springer-Verlag, 1989. 226 p. DOI: $10.1007 / 978-1-4613-9637-6$

15. Le Blanc M., Fréshette M. Male criminal activity from childhood through youth. New York, Springer-Verlag, 1988. 228 p. DOI: $10.1007 / 978-1-4612-3570-5$

16. Mawby R. I. Burglary. Devon, UK, Willan Publishing, 2001. 213 p.

17. United States Bureau of the Census: Statistical abstract of the United States. 117th ed. Washington, DC, Hoovers Inc, 1997. 1022 p.

18. Kube E., Schuster L. Le vandalisme en milieu urbain: importance, portée et contexte du phenomena: mesures possibles de prévention. Strasbourg, Comité Européen pour les Problèmes Criminels, 1984. 24 p.

19. Lorenz M. Vandalismus als Alltagsphänomen. Bonn, Bundeszentrale für Politische Bildung, 2012. $157 \mathrm{p}$.

20. Stuart G. Conflict and homeless youth. Youth Studies Australia, 1994, V. 13, no. 2, pp. 27-30.

21. Tavecchio L. W. C. Moral judgement and delinquency in homeless youth. Journal of Moral Education, 2010, V. 28, no. 1, pp. 63-79. DOI: 10.1080/030572499103313

22. Omaev B. Kh. The concept of vandalism and personal features in vandals. Obrazovanie i pravo - Education and Law, 2013, no. 5 (45) - 6 (46), pp. 168-173 (in Russian).

23. Robinson S. L., Bennett R. J. A Typology of deviant workplace behaviors: A multidimensional scaling study. The Academy of Management Journal, 1995, V. 38, no. 2, pp. 555-572. DOI: $10.2307 / 256693$

24. Cohen S. Sociological approaches to vandalism. In: C. Levy-Leboyer (ed.) Vandalism, behaviour, and motivations. Amsterdam, New York, Oxford, North Holland, 1984, pp. 51-62.

25. Levy T., Tziner A. When destructive deviance in the workplace becomes a liability: a decisional behavioral model. Quality and Quantity, 2011, V. 45, Issue 1, pp. 233-239. DOI: 10.1007/s11135-009-9277-0

26. Coffin B. Breaking the silence on white collar crime. RiskManagement, 2003, V.50, no. 8, pp. 6. Available at: https://www.questia.com/magazine/1G1-107762284/ breaking-the-silence-on-white-collar-crime (Accessed 14 February 2018).

27. Cohen S. Property destruction: Motives and meanings. In: C. Ward (ed.) Vandalism. London, The Architectural Press, 1973, pp. 23-53.

28. Canter D. V. Fires and human behavior. New York, John Wiley and Sons Ltd, 1980. 356 p.

29. Baron R. M., Fisher J. D. The equity-control model of vandalism: a refinement. In: C. Levy-Leboyer (ed.) Vandalism, behaviour and motivations. Amsterdam, New York, Oxford, North Holland, 1984, pp. 63-76. 
30. Weinmayr V. M. Vandalism by design: A critique. Landscape Architecture, 1969, V. 59, p. 286.

31. Plutchik R. Emotion: A psychoevolutionary synthesis. New York, Harper \& Row, 1980. 440 p.

32. Plutchik R. The measurement of emotions. Acta Neuropsychiatrica, 1997, V. 9, Issue 2, pp. 58-60. DOI: 10.1017/S0924270800036802

33. Plutchik R. The emotions: Facts, theories and a new model. New York, Random House, 1962. 232 p.

34. McDougall W. An introduction to social psychology. 14th ed. Boston, MA, US, John W Luce \& Company, 1921. 410 p.

35. Gulevich O. A. Counter-productive activity at organizations: Definition, types, and factors. Organizatsionnaya psikhologiya - Organizational Psychology, 2013, V. 3, no. 4, pp. 49-58 (in Russian).

36. Kaukiainen A., Salmivalli C., Björkqvist K., Österman K., Lahtinen A., Kostamo A., Lagerspetz K. Overt and covert aggression in work settings in relation to the subjective well-being of employees. Aggressive Behaviour, 2001, V. 27, no. 5, pp. 360-371. DOI: 10.1002/ab.1021

37. Pietersen C. A Diagnostic approach to measuring and managing workplace aggression. SA Journal of Human Resource Management, 2005, V. 3, no. 1, pp. 1-5. DOI: 10.4102/sajhrm.v3i1.52

38. Kruzhkova O. V., Devyatovskaya I. V. Psychological aspects of highlighting the emotional basis of organizational vandalism. In: A. L. Zhuravlev, V. A. Kol'tsova (eds.) Fundamental'nye i prikladnye issledovaniya v sovremennoi psikhologii: rezul'taty i perspektivy razvitiya [Fundamental and applied research in modern psychology: results and prospects]. Moscow, Institute of Psychology, RAS Publ., 2017, pp. 1839-1846.

39. Ortega Escobar J., Alcázar Córcoles M. T. Neurobiology of aggression and violence [Neurobiología de la agresión y la violencia]. Anuario de Psicología Jurídica, 2016, V. 26, no. 1, pp. 60-69. DOI: 10.1016/j.apj.2016.03.001

40. Rosell D. R., Siever L. J. The neurobiology of aggression and violence. CNS Spectrums, 2015, V. 20, Special Issue 3, pp. 254-279. DOI: $10.1017 /$ S109285291500019X

41. Özer Ö., Uğurluoğlu Ö., Saygılı M., Sonğur C. The impact of work alienation on organizational health: A field study in health sector. International Journal of Healthcare Management, 2017. DOI: 10.1080/20479700.2017.1312804

42. Welford A. T. Ergonomics: Where have we been and where are we going: I. Ergonomics, 1976, V. 19, Issue 3, pp. 275-286. DOI: 10.1080/00140137608931543

43. Csikszentmihalyi M., Larsen R. Intrinsic rewards in school crime. Applications of Flow in Human Development and Education. Dordrecht, Springer, 2014, pp. 271-284. DOI: 10.1007/978-94-017-9094-9 14 


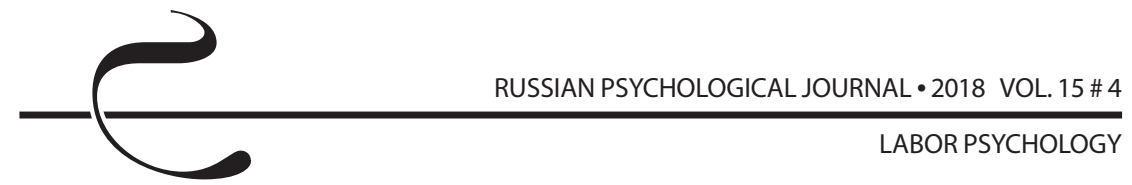

44. Gudkov L. D. Rebirth of a "Soviet man" (a case of a research project of the Levada Center). Odysseus: Man in history - Odysseus: Man in History, 2007, no. 1, p. 398 (in Russian).

45. Schilling J. Organisationaler Zynismus als Herausforderung für Führungskräfte: Umgang mit destruktiven Einstellungen von Mitarbeitern. In: A. Gourmelon (Hrsg.) Herausforderung Führung - führen wollen, führen können, schwierige Situationen meistern. Heidelberg, Rehm, 2016, pp. 21-36.

46.Zábrodská K., Květon P. Šikana na pracovišti v prostředí českých univerzit: výskyt, formy a organizač ní souvislosti. Sociologický časopis / Czech Sociological Review, 2012, V. 48, no. 4, pp. 641-668.

47. Momand H. Mobbing in der Arbeitswelt: Ursachen, Folgen und mögliche Lösungsansätze für ein verbessertes Arbeitsklima. Hamburg, Diplomica Verlag, 2011. $207 \mathrm{p}$.

48. Pryadein V. P. Psychological, pedagogical, and social aspects of the sense of duty. Pedagogicheskoe obrazovanie v Rossii - Pedagogical Education in Russia, 2015, no. 9, pp. 65-71 (in Russian).

49. Yarushkin N. N., Satonina N. N. Social fear as a regulator of individuals' responsible behaviour. Vestnik Samarskoi gumanitarnoi akademii. Seriya: Psikhologiya - Bulletin of the Samara Humanitarian Academy. Series: Psychology, 2007, no. 1, pp. 78-84 (in Russian).

50. Karpov A. V. Psikhologiya menedzhmenta [Psychology of management]. Moscow, Gardariki Publ., 2005. 584 p.

51. Roos H.-E. Vandalism as a Symbolic Act in Free Zones. In: C. Harriet H., J. Darryll J., \& B. Martha H. (eds.) Vandalism: Research, Prevention and Social Policy. Seattle, US Dept. of Agruculture, Pacific Northwest Research Station and University of Washington, 1992, pp. 71-87. Available at: http://portal. research.lu.se/portal/files/5546900/802127.pdf (Accessed 14 February 2018).

52. Bobocel D. R. Coping with unfair events constructively or destructively: The effects of overall justice and self-other orientation. Journal of Applied Psychology, 2013, V. 98 (5), pp. 720-731. DOI: 10.1037/a0032857 